\title{
Médiévales
}

Langues, Textes, Histoire

70 | printemps 2016

Lieux d'hygiène et lieux d'aisance en terre d'Islam (VII $\mathrm{e}_{-}$ $\mathrm{XV}^{\mathrm{e}}$ siècle)

\section{Patrick GILLI, Droit, humanisme et culture politique dans l'Italie de la Renaissance}

Montpellier, Presses universitaires de la Méditerranée, 2014, 453 p. (« Histoire et sociétés »)

\section{Clémence Revest}

\section{CpenEdition}

\section{Journals}

Édition électronique

URL : http://journals.openedition.org/medievales/7760

DOI : $10.4000 /$ medievales. 7760

ISSN : 1777-5892

Éditeur

Presses universitaires de Vincennes

Édition imprimée

Date de publication : 23 juin 2016

Pagination : 279-280

ISSN : 0751-2708

Référence électronique

Clémence Revest, « Patrick GıLı, Droit, humanisme et culture politique dans I'Italie de la Renaissance », Médiévales [En ligne], 70 I printemps 2016, mis en ligne le 20 juillet 2016, consulté le 23 septembre 2020. URL : http://journals.openedition.org/medievales/7760 ; DOI : https://doi.org/10.4000/ medievales. 7760

Ce document a été généré automatiquement le 23 septembre 2020.

Tous droits réservés 


\section{Patrick GILLI, Droit, humanisme et culture politique dans l'Italie de la Renaissance}

Montpellier, Presses universitaires de la Méditerranée, 2014, 453 p.

(« Histoire et sociétés »)

Clémence Revest

\section{RÉFÉRENCE}

Patrick GILLI, Droit, humanisme et culture politique dans l'Italie de la Renaissance,

Montpellier, Presses universitaires de la Méditerranée, 2014, 453 p. (« Histoire et sociétés »)

1 Cet ouvrage aussi riche qu'utile recueille dix-neuf articles publiés par Patrick Gilli entre 1998 et 2012, auxquels sont ajoutés deux inédits, un avant-propos et deux index. Les différents domaines d'enquête explorés par l'historien depuis une quinzaine d'années y sont rassemblés sous un titre qui, à la fois, en souligne les grands axes thématiques (humanisme, droit, politique), pose le problème central de leur interrelation et signale ce qui en est le terrain principal - l'Italie des $\mathrm{XIV}^{\mathrm{e}}-\mathrm{Xv}^{\mathrm{e}}$ siècles (avec quelques excursions vers le royaume de France), foyer de la civilisation de la Renaissance, mais aussi lieu d'expériences de gouvernement multiples (parmi lesquelles les communes et les seigneuries), espace de floraison des universités et théatre majeur de l'histoire de l'Église, notamment du Grand Schisme d'Occident. Comme il le rappelle au cours de l'avant-propos qui évoque brièvement son parcours de chercheur, Patrick Gilli n'a eu de cesse d'interroger l'histoire des cultures savantes et des idées politiques à la fin du Moyen Âge à la lumière de leurs enjeux sociétaux contemporains, en s'écartant d'une vision polarisée sur les filiations littéraires et idéologiques. De la mise en série de ses travaux émerge ainsi une histoire intellectuelle influencée par la sociologie et nourrie d'une lecture croisée des sources, qui articule en particulier l'étude de l'émergence de 
modèles dominants de pensée aux usages politiques qui en sont faits et aux contextes institutionnels (chancelleries, collèges universitaires, sociétés de cour) dont ils sont issus, en accordant une large place aux dynamiques de la compétition sociale entre lettrés. La rivalité entre humanistes et juristes, la construction des archétypes politiques de l'orateur ou de l'ambassadeur, le rôle assigné aux compétences savantes dans l'exercice de l'autorité politique, les rapports complexes entre humanisme et institution ecclésiastique constituent quelques-unes des pistes de réflexion mises en avant par une recherche au long cours qui, fondamentalement, révèle les profonds bouleversements du statut des intellectuels et les questions qu'une telle mutation soulève.

Divisé en six parties («Les cadres de production du savoir », « Le droit et l'humanisme : savoirs en compétition", "Culture politique et juridique: discours croisés", "Humanisme, Église et droit canonique », "Diplomatie et culture au temps de l'humanisme », «En-deçà et au-delà des Alpes, regards croisés »), le recueil fait alterner des articles de synthèse, telle une remarquable présentation de l'humanisme français à l'époque du concile de Constance, des contributions de large ampleur problématique et thématique (à l'exemple de celle consacrée au rôle des juristes au service des Angevins de Naples dans la construction idéologique de la monarchie) et des publications à visée plus ponctuelle, pour certaines axées sur le commentaire d'un texte édité en annexe, à l'instar du De laudibus eloquentiae de Cosma Raimondi (ca 1431-1432), qui constitue un bel exemple de la définition par les humanistes d'un modèle idéal d'orator formé à la rhétorique antique, par opposition directe à la situation dominante des juristes dans le champ politique. L'auteur revient à plusieurs reprises sur la plasticité du mouvement humaniste, ou sur «l'extrême ductilité de la notion de studia humanitatis» (p.34), en montrant, d'une part, comment des thèmes traditionnels sont repris et réadaptés en quelque sorte par les lettrés qui prônent la redécouverte de l'Antiquité, d'autre part, comment ce qui se présentait à l'origine comme un modèle culturel alternatif a progressivement été constitué en nouveau paradigme de l'establishment.

3 La capacité de la pensée humaniste à réactualiser des débats anciens à partir d'outils savants caractéristiques apparaît avec netteté aussi bien en ce qui concerne l'éloge de la vita contemplativa chez Cristoforo Landino ou Leon Battista Alberti, désormais entendue comme le refuge désenchanté du lettré face à un impossible engagement civique, qu'à propos du républicanisme florentin promu par Leonardo Bruni, cet «humanisme civique» si discuté dont Patrick Gilli rappelle qu'il traduit surtout la fermeture politique consécutive à la révolte des Ciompi. De même, le problème délicat d'un supposé "anticléricalisme humaniste" se trouve-t-il désamorcé au fil d'un passage en revue suggestif des œuvres à disposition, dont celles de Poggio Bracciolini, qui fait ressortir l'adéquation de ces discours avec des critiques et remises en cause largement répandues et admises au sein même de l'Église, constituant une sorte de tradition de dénigrement sans réelle portée subversive. L'historien interroge encore, par diverses voies d'accès, les mécanismes relativement méconnus de l'institutionnalisation de l'humanisme, tout spécialement de son intégration dans le système universitaire, au-delà des célèbres attaques lancées par Pétrarque. Le cas de l'essor d'un humanisme juridique, étudié au cours d'un article particulièrement stimulant («Humanisme juridique et science du droit au $\mathrm{Xv}^{e}$ siècle »), est révélateur d'un effort de conciliation et de domestication mené par les tenants des disciplines traditionnelles à l'égard d'un paradigme humaniste en pleine expansion, en passe de 
s'imposer comme un outil indispensable de l'honorabilité savante: face à la concurrence, les juristes font en sorte de "relever le défi des humanistes " (p. 144) et de conforter leur position de force. Les divers projets scientifiques et politiques, dont le fameux manuscrit des Pandectes pisanes fait l'objet entre $\mathrm{le} \mathrm{xv}^{\mathrm{e}}$ et le $\mathrm{xvI}$ siècle, illustre à son tour, dans une contribution à part, les tensions qui fondent les rapports entre studia humanitatis et scientia legalis à l'orée de la Renaissance.

Le prestige et l'influence politiques des juristes, étroitement liés à leur appartenance aux élites urbaines et curiales, sont eux-mêmes mis en lumière avec acuité à travers la production des consilia et la constitution des collèges de docteurs. Les consilia produits par Baldo degli Ubaldi à l'occasion de l'octroi du titre ducal à Gian Galeazzo Visconti en 1395 permettent ainsi de prendre la mesure à la fois de l'autorité de l'expertise intellectuelle apportée par le consultor et de l'immédiateté de sa finalité politique. L'historien souligne surtout la souplesse et la créativité qui caractérisent une pratique savante en prise avec l'actualité, comme c'est le cas dans les premières années de la crise du Grand Schisme d'Occident, propices à la floraison de consilia pour certains très inventifs (à l'exemple du De fletu Ecclesiae de Jean de Legnago). Enfin, sans prétendre rendre compte de l'intégralité des sujets traités (parmi lesquels la question du droit de la naturalisation ou celle du rapport entre activité juridique et activité poétique chez Cino da Pistoia), on peut signaler que la diplomatie constitue un autre terrain de choix pour l'historien. Celui-ci explore en effet dans quatre de ses travaux les ressorts de la définition progressive et ambiguë de la fonction d'ambassadeur, au moment où les pratiques de légation se développent et gagnent en autonomie. La lecture, notamment, des opuscules composés par Martino Garati, Ermolao Barbaro et Bernard de Rosier au cours $\mathrm{du} \mathrm{xv}^{\mathrm{e}}$ siècle, met au jour les difficultés qu'éprouvent alors les lettrés à faire coïncider l'élaboration théorique à une réalité en évolution, pour ce qui concerne tant l'analyse juridique de la mission de représentation que la conception éthique d'une figure nouvelle de l'homme d'État. De ces ajustements idéologiques encore tâtonnants naît l'idéal d'un officier vertueux, éloquent et compétent, incarné par Giannozzo Manetti dans le portrait qu'en dépeint Naldo Naldi.

Multiples et précieux sont donc les apports historiographiques des travaux présentés dans un recueil qui facilite grandement l'accès à des publications dispersées ou encore à paraitre et qui, surtout, manifeste la cohérence et la portée d'un projet scientifique de longue haleine. 